\title{
Evolução dos Índices de Proliferação Celular e Apoptose em Placentas de Ratas com Diabete Grave: Relação com a Glicemia Materna e o Resultado Perinatal
}

Autor: Elaine Cristina Nunes Fagundes Costa

Orientador: Profa. Dra. Marilza Vieira Cunha Rudge

Tese de Doutorado apresentada no Programa de Pós-Graduação em Ginecologia e Obstetrícia, Área de Concentração: Obstetrícia - Departamento de Ginecologia e Obstetrícia da Faculdade de Medicina de Botucatu, UNESP, em 6 de dezembro de 2002.

Não existem relatos sobre estudo concomitante de proliferação celular e apoptose em placentas de ratas com diabete grave, modelo de restrição de crescimento intra-uterino (RCIU). O objetivo foi analisar os índices de proliferação celular e de apoptose no $18^{\circ}$ e $21^{\circ}$ dias de prenhez de ratas diabéticas em relação aos níveis glicêmicos maternos e ao resultado perinatal. Foram colhidas 100 placentas de 20 ratas Wistar divididas em quatro grupos experimentais: de acordo com a presença ou não de diabete, induzido pelo Streptozotocin e com a idade de resolução da prenhez no $18^{\circ}$ ou $21^{\circ}$ dias: controle e diabético de 18 e 21 dias. A proliferação celular analisada pelo método do PCNA e a apoptose pelos métodos do TUNEL e HE foram correlacionados com à média glicêmica materna e o peso dos recémnascidos. Os dados foram comparados pelos testes $t$ ou de Mann-Whitney. Os resultados evidenciaram que os índices de proliferação celular e apoptose pelos métodos de TUNEL e HE foram menores nas placentas de ratas diabéticas de 21 dias e diminuiram do $18^{\circ}$ para o $21^{\circ}$ dia. A análise da apoptose pelo TUNEL, por área de tecido placentário, foi mais adequada que o $\mathrm{HE}$, pela rapidez na leitura das lâminas e pelos maiores índices observados. Os índices de apoptose e proliferação celular não se correlacionaram com o peso do recémnascido e com a média glicêmica materna.

Palavras-chave: Diabete melito. Apoptose. Placenta.

\section{Estudo do Valor Prognóstico da Expressão Imunoistoquímica de p53 e p16 no Carcinoma do Colo do Útero Estádios Ib e Ila.}

Autor: Dr.Pablo Roberto Novik.

Orientador: Prof. Dr.Ademar Lopes

Tese desenvolvida na Fundação Antonio Prudente, no Centro de Tratamento e Pesquisa Hospital do Câncer A. C. Camargo. Apresentada em 12 de maio de 2003.

O carcinoma do colo do útero representa doença de grande importância devido à sua alta incidência e mortalidade nos países em desenvolvimento. Vários fatores prognósticos clínicos e anatomopatológicos vêm sendo estudados e correlacionados com a sobrevida das pacientes portadoras de carcinoma do colo do útero. Este trabalho visa estudar o valor prognóstico da expressão imunoistoquímica de p53 e p16, que são proteínas que atuam no controle do ciclo celular. Duzentas e quarenta e seis pacientes portadoras de carcinoma de colo do útero nos estádios Ib e IIa foram estudadas, correlacionando a expressão imunoistoquímica de p53 e de p16 com variáveis clínicas e anatomopatológicas: estadiamento clínico, tipo histológico, metástase linfonodal, idade, menopausa e número de gestações, variáveis que tiveram significância como fatores prognósticos. As pacientes encontravam-se $90,2 \%$ no es- tádio Ib e 9,8\% no estádio IIa (sobrevida livre de doença de $80,53 \%$ e 90,91\%, respectivamente com $\mathrm{p}=0,2496$ ). Não houve diferença quanto à positividade imunoistoquímica para p53 e p16 nos estádios Ib e IIa $(9,5 \%$ e $4,2 \%$ para p53 com p=0,388, e $86,5 \%$ e $83,3 \%$ para $\mathrm{p} 16$ com $\mathrm{p}=0,671)$. A expressão imunoistoquímica de p53 e p16 não se encontra alterada quando comparada com as variáveis clínicas e anatomopatológicas estudadas: tipo histológico, metástase linfonodal, idade menor de 35 anos, número de gestações e menopausa. Não houve correlação entre a expressão imunoistoquímica de p16 e p53 com o prognóstico das pacientes portadoras de carcinoma do colo do útero nos estádios Ib e IIa.

Palavras-chave: Neoplasias do colo uterino. Proteína p53. Proteína p16. Prognóstico. 